\title{
The Study of using Wind Energy to Hydropower Designs with Pump
}

\section{Badaluta Minda}

Politehnica University of Timisoara, Hydrotechnical Department, Timisoara, Timis, 300022, Romania

*Corresponding author: C Badaluta Minda, Politehnica University of Timisoara, Hydrotechnical Department, Timisoara, Timis, 300022, Romania, Tel: +40256-404096; E-mail: badaluta_minda@yahoo.com

Recieved date: Jan 26, 2016; Accepted date: Feb 03, 2016; Published date: Feb 10, 2016

Copyright: ( 2016 Minda CB. This is an open-access article distributed under the terms of the Creative Commons Attribution License, which permits unrestricted use, distribution, and reproduction in any medium, provided the original author and source are credited.

\begin{abstract}
New hydropower with pump can be a continuous development within the national energy system. Their principle is to cheap energy consumption power P1 E1 produced at the base of the schedule task for pumping water from a reservoir situated at odds, in a lowered reservoir situated at height. While producing more energy expensive peak $\mathrm{E} 2$ to power $\mathrm{P} 2$ is achieved by whirling such volumes.

The difference in cost between the basic energy absorbed by pumping the peak produced at whirling ensures profitability of these facilities. Regarding the current hydropower system nationwide to establish the existence of hydro-technical systems with pumping and gravitational systems this can be turned into ones with pumping. In analysing the conditions of work opportunity and search engine optimization of wind energy at the base of hydropower facilities with pumping system may be transformed-High Barzava. Limits are fixed to the unit cost of wind energy is competitive for its use as a primary source.
\end{abstract}

Keywords: Wind energy; Hydropower system with pumping and gravity; Primary source; Reservoir

\section{Introduction}

In an arrangements scheme of hydropower plant with pump, turn the energy reservoir hydraulic potential energy, kinetic energy respectively by rotating turbine hydropower plant and finally into electric power.

In periods with low electricity consumption (at night) operates the pumping aggregates, which pumps water to the upper reservoir by storing energy, and in periods with high power consumption (during peak periods) operating system whirling of water stored in the pumping phase to produce electricity. A hydro-electric power which utilizes a fall depends on two factors: the flow of water and the gross loss, the difference between the elevation where this source is restores and the place where it is returned to the environment through a whirling. In areas where we have wind energy we can use at primary (pumping), when its cost is lower than the peak energy (Figure 1).

In 2010, Romania has adopted the law for the promotion of renewable energy, an important step in the development of renewable energy in our country. Estimated annual energy potential of wind in Romania is estimated at around $23 \mathrm{TWh}$, and areas of interest are those in which the average wind speed is at least equal to $4 \mathrm{~m} / \mathrm{s}$.

At the beginning of 2012 in Romania there were over 1000 wind turbines that produce $3 \%$ of total energy [1]. Windings power stations in our country are producing an average of 150-200 megawatts/hour. The cost of wind energy is 170 euros per megawatt/hour, nearly three times as much in relation to energy produced from hydroelectric power plants.

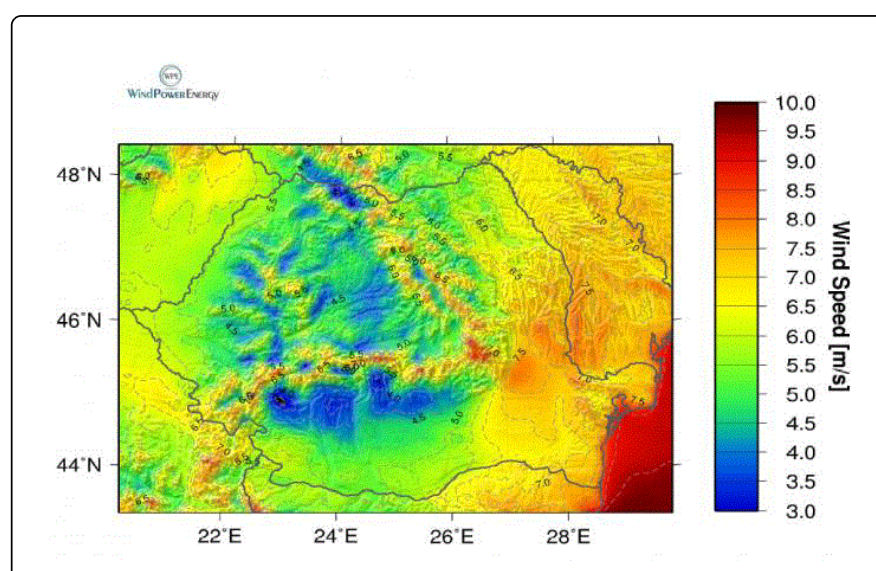

Figure 1: Wind map Romania, potential of 14,000 MW.

On the basis of the evaluation and interpretation of the data recorded in Romania you can mount the wind installations with a capacity of up to $14,000 \mathrm{MW}$, which means a contribution of electricity almost 23,000 GWh/year [2-4]. According to a study of ErsteGroup, the country's wind power potential, estimated at 14,000 MW, is the largest in South-Eastern Europe and the second in Europe [5].

\section{Analysis of Schemes for Hydropower Facilities}

The necessity of construction of AHP (arrangement scheme with pumping) results and the need to cover the variable energy consumption over time, both in terms of variation in daily and seasonal and annual consumption. After the operation, AHP were classified [6]: closed circuit, where pumping volume equal to the volume of gross, and whirling falls are equal

$$
\left(\mathrm{V}_{1}=\mathrm{V}_{2} ; \mathrm{H}_{\mathrm{b} 1}=\mathrm{H}_{\mathrm{b} 2}\right) \text {. }
$$


Citation: Minda CB (2016) The Study of using Wind Energy to Hydropower Designs with Pump. Hydrol Current Res 7: 224. doi:

Page 2 of 5

Closed circuit-mixed: $\mathrm{V}_{2}=\mathrm{V}_{1}+\Delta \mathrm{V} ; \mathrm{H}_{\mathrm{b} 1}=\mathrm{H}_{\mathrm{b} 2}$

With open circuit: $\mathrm{V}_{1}=\mathrm{V}_{2} ; \mathrm{H}_{\mathrm{b} 2}=\mathrm{H}_{\mathrm{b} 1}+\Delta \mathrm{H}$

Open-circuit-mixed: $\mathrm{V}_{2}=\mathrm{V}_{1}+\Delta \mathrm{V} ; \mathrm{H}_{\mathrm{b} 2}=\mathrm{H}_{\mathrm{b} 1}+\Delta \mathrm{H}$

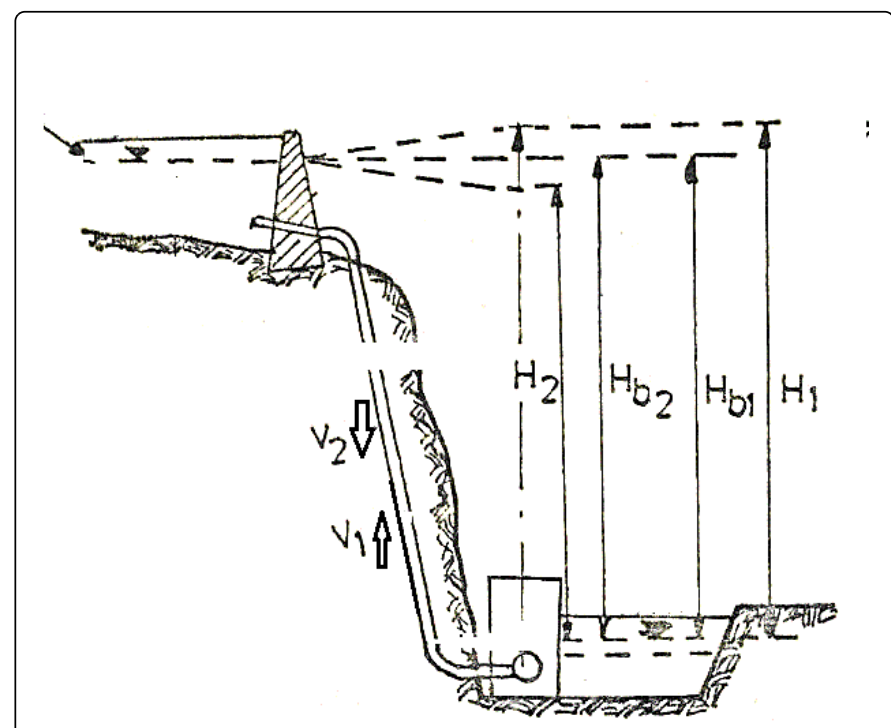

Figure 2: AHP with closed circuit.

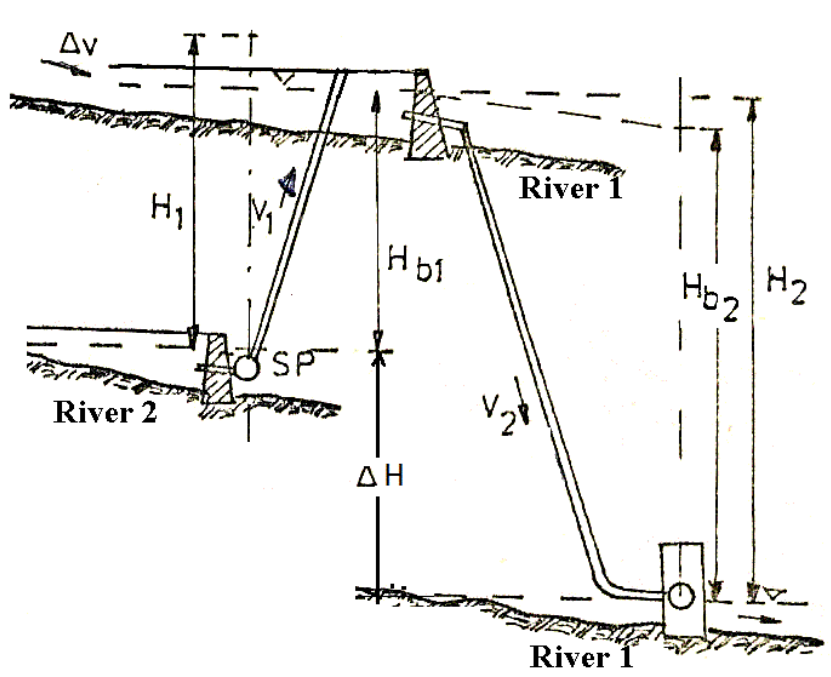

Figure 3: AHP with open circuit.

The principle of these schemes with hydropower (AHP) is the consumption of cheap energy $\mathrm{E}_{1} \mathrm{P}_{1}$ power produced at the base of the graph of the task for pumping water from a lake located the build-up descended into a reservoir located high and energy more expensive peak power $\mathrm{P}_{2} \mathrm{E}_{2}$, whirling volumes thus accumulated. The difference in cost between the energy absorbed by the base and the peak primary produced from secondary arrangement ensure profitability. Cycle energy transformations through AHP consist of two distinct phases, namely:
- mayor phase (pumping) in which energy network are taken power, the water being pumped from the lower reservoir in the superior lake(Figures 2 and 3);

- phase relation (whirling) in which the water stored in Lake superior is being restored to power whirled network;

In certain circumstances become cost-effective AHP [7]:

\section{AHP closed circuit}

AHP Closed circuit characterized by driving head equal $\left(\mathrm{H}_{\mathrm{b} 1}=\mathrm{H}_{\mathrm{b} 2}=\mathrm{H}_{\mathrm{b}}\right)$,

$\mathrm{H}_{1}>\mathrm{H}_{2}$-waterfall net with $\mathrm{H}_{1}=\mathrm{H}_{\mathrm{b}}+\mathrm{h}_{\mathrm{r} 1}$ and $\mathrm{H}_{2}=\mathrm{H}_{\mathrm{b}}-\mathrm{h}_{\mathrm{r} 2} ; \mathrm{Q}_{\mathrm{i} 1}<\mathrm{Q}_{\mathrm{i} 2^{-}}$ installed debits for $\mathrm{P}_{1}<\mathrm{P}_{2}$;

$$
\mathrm{E}_{2}=\mathrm{E}_{1 . \mathrm{n}},(\mathrm{y}=0.60-0.70) \text {. }
$$

The loss of energy is:

$$
\Delta \mathrm{E}=\mathrm{E}_{1}-\mathrm{E}_{2}=(1-\eta) \mathrm{E}_{1}=(0.3-0.4) \mathrm{E}_{1}[\mathrm{KWh} / \text { cycle }][8]
$$

Considering the ratio between peak energy value $\mathrm{p}_{2}$ energy produced and $\mathrm{p}_{1}$ base consumed for pumping 4 ratios, gross income and expenses of the pumping energy will be:

$$
\frac{E_{2} \cdot p_{2}}{E_{1} \cdot p_{1}}=\eta \frac{p_{2}}{p_{1}}=0.65 \cdot 4=2.6
$$

\section{AHP mixt closed circuit}

AHP mixt closed circuit is inserted into the addition volume $\Delta \mathrm{V}$ $\left(\mathrm{m}^{3} /\right.$ cycle) from rainfall collected on hillsides or in capturing some of the tributaries, and in this case the energies will be:

$$
\begin{aligned}
& E_{1}=\frac{k}{\eta_{1}} V_{1} \cdot H_{b} \quad[\mathrm{KWh} / \text { cycle }] \\
& E_{2}=k\left(V_{1}+\Delta V\right) H_{b} \cdot \eta_{2}[\mathrm{KWh} / \mathrm{cycle}] \\
& \frac{E_{2}}{E_{1}}=\frac{V_{1}+\Delta V}{V_{1}} \eta_{1} \cdot \eta_{2}=\left(1+\frac{\Delta V}{V_{1}}\right) \eta_{1} \cdot \eta_{2}
\end{aligned}
$$

By writing $\eta=\eta_{1} \cdot \eta_{2}$ results: $E_{2}=E_{1}\left(1+\frac{\Delta V}{V_{1}}\right) \eta$

Energy loss in a cycle will be:

$$
\Delta E=E_{1}-E_{2}=E_{1}\left[1-\left(1+\frac{\Delta V}{V_{1}}\right) \eta\right][K W h / c y c l e]
$$

Taking into consideration the overall efficiency $\eta=0.65[7]$ it has been established that

If $\Delta \mathrm{V}>0.54 \mathrm{~V}_{1}$, AHP produces more energy than the energy consumed for pumping.

\section{AHP with open circuit}

The energies will be:

$$
\begin{aligned}
& E_{1}=\frac{k}{\eta_{1}} V_{1} \cdot H_{b 1}[k W h / c y c l e] \\
& E_{2}=k V_{1}\left(H_{b 1}+\Delta V\right) \cdot \eta_{2} \\
& \frac{E_{2}}{E_{1}}=\frac{H_{b 1}+\Delta H}{H_{b 1}} \eta_{1} \cdot \eta_{2}=\left(1+\frac{\Delta H}{H_{b 1}}\right) \eta \quad \rightarrow E_{2}=E_{1}\left(1+\frac{\Delta H}{H_{b 1}}\right) \eta
\end{aligned}
$$


Citation: Minda CB (2016) The Study of using Wind Energy to Hydropower Designs with Pump. Hydrol Current Res 7: 224. doi: 10.4172/2157-7587.1000224

Page 3 of 5

Loss of energy will be;

$$
\Delta E=E_{1}-E_{2}=E\left[1-\left(1+\frac{\Delta H}{H_{b 1}}\right) \eta\right]
$$

$\frac{\Delta H}{H_{b 1}}>0.43-0.67 ; \mathrm{E}_{2}>\mathrm{E}_{1}$ Produces more energy than consumed energy for pumping.

\section{AHP open mixed circuit}

Captures the reservoir an additional volume $(\Delta \mathrm{V})$ to the same energy $E_{1}$ at primary, and the energy produced to secondary will be [9]:

$$
E_{2}=k \cdot \eta_{2}\left(\frac{V_{1}+\Delta V}{V_{1}}\right)\left(1+\frac{\Delta H}{H_{b 1}}\right)
$$

The ratio of energies:

$$
\begin{aligned}
& \frac{E_{2}}{E_{1}}=\left(1+\frac{\Delta V}{V_{1}}\right)\left(1+\frac{\Delta H}{H_{b 1}}\right) \eta \\
& \text { If }\left(1+\frac{\Delta V}{V 1}\right)\left(1+\frac{\Delta H}{H_{b 1}}\right)>\frac{1}{\eta} \rightarrow E_{2}>E_{1}
\end{aligned}
$$

\section{Case Study}

\section{Geographic location and characteristics}

River Barzava has a basin with an area of $971 \mathrm{~km}^{2}$, all being small tributaries with areas why not exceeding 100 square kilometres. Due to both the large industrial and drinking water in the municipality of Resita hydro technical works were required, aimed at supplementing water for using stock by transferring some flows from neighbouring basins and redistribution of leakage through the dam Lakes. The system now comprises hydro technical Barzava Superior(Figure 4) channel Nera $\left(6,575 \mathrm{~km}\right.$. length, peak discharge $\left.1.75 \mathrm{~m}^{3} / \mathrm{s}\right)$ with the role of one of some water flows from the Nera river basin catchment area in Barzava; - Semenic-channel $\left(\mathrm{L}=23.3 \mathrm{~km}, \mathrm{Q}=1.43 \mathrm{~m}^{3} / \mathrm{s}\right)$ with the role of one of certain flows of water from the water catchment basin in Barzava - accumulation "Trei Ape" (6,008 million gross volume $\mathrm{m}^{3}$. useful volume 4,363 mil.cm) situated on the upper course of Timis, aiming for an additional reserve of water in the catchment area Barzava after transfer through pump station and Semenic channel. Gozna accumulation $\left(12,357\right.$ mil.m ${ }^{3}$ gross volume; volume useful of 10,269 mil.m ${ }^{3}$ ) Valiug accumulation (1, 06 gross Volume mil.m ${ }^{3}$, volume useful $0,916 \mathrm{mil} . \mathrm{m}^{3}$, maximum outflow of $87 \mathrm{~cm} / \mathrm{s}$, emptying the bottom is clogged). Accumulation Secu (gross volume $11,109 \mathrm{~m}^{3}$, maximum outflow of $\left.135 \mathrm{~m}^{3} / \mathrm{s}\right)$. The system comprises a series of canals and water transport (main Channel, channel Gozna, etc.) with the role of transporting water to hydroelectric and the water utilizations. Crainicel, Breazova and Grebla hydro powers has arranged in cascade and utilizes a total waterfall of $323 \mathrm{~m}$.

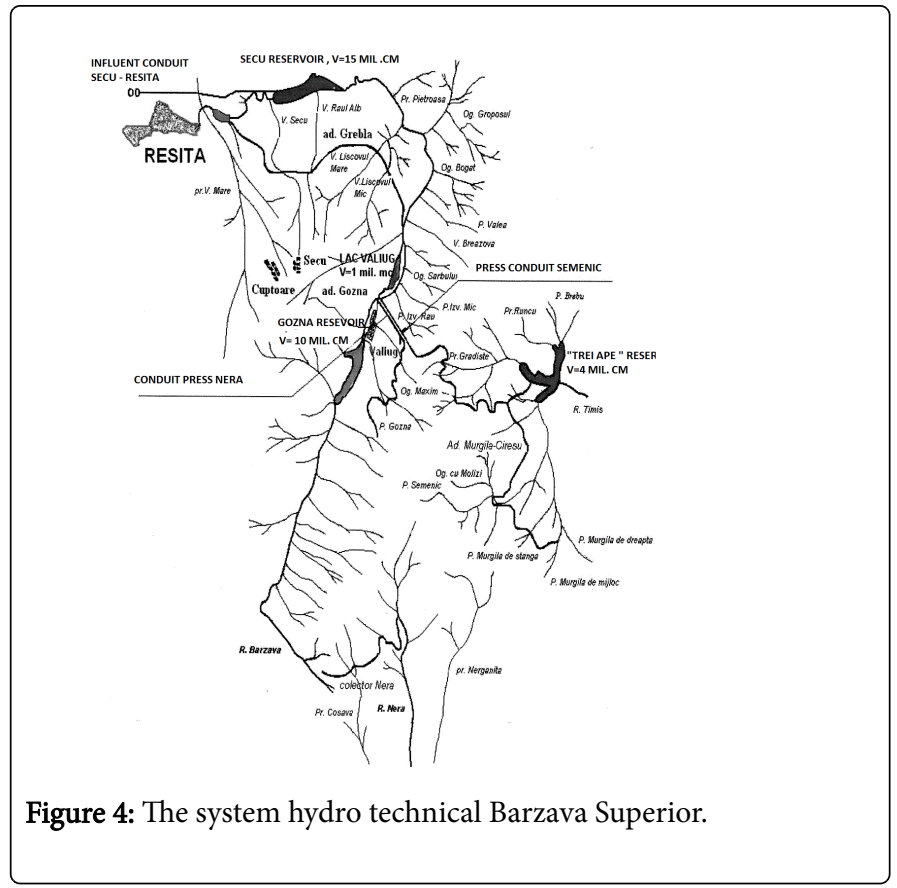

Hydro powers Crainicel, Grebla andBreazova mostly natural debt collected from ponds Barzava, Timis, Nera. Their arrangement in a tandem allows the use of the natural loss of the river Barzava, although not managed just a capitalization $40 \%$ of the natural waterfall of $323 \mathrm{~m}$, which results in possible future expansions of the hydro arrangements from the point of view of energy.

\section{Analysis Results and Discussion}

Mixed open circuit (Figure 5) was put in operation for the derivation of water from the river Timis in Barzava through pumping from the three UHE (Crainicel, Breazova and Grebla) located in the waterfall on the river Barzava and other utilizations (water supply, industry, etc.).

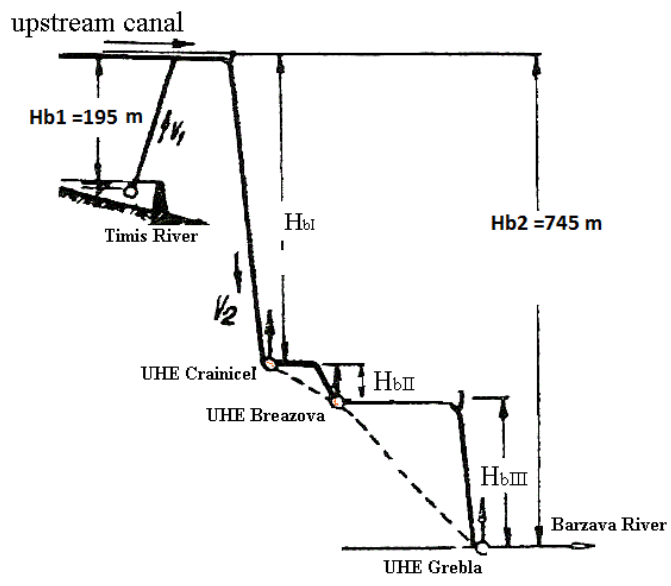

Figure 5: The arrangement of Barzava River. 
If you apply the theoretical methodology for system Barzava-Timis, where:

-Mayor consists of "Trei Ape" reservoir located on the river Timis, delivery pipe and Electro pumps that upset jumping $\mathrm{V}_{1}$ towards upstream channel with $\mathrm{H}_{\mathrm{b} 1}=195 \mathrm{~m}$

-The second arrow is composed of three hydroelectric power plants located in the Waterfall on the river Barzava with $\mathrm{H}_{\mathrm{b} 2}=745 \mathrm{~m}$ and $\Delta \mathrm{H}=550 \mathrm{~m}$

$$
\frac{E_{2}}{E_{1}}=\left(1+\frac{\Delta H}{H_{b 1}}\right) \eta=0.65\left(1+\frac{550}{195}\right)=2.3
$$

From the above date results report energies (relationship 15) being 2.3 , so the energy produced by the $E_{2}$ is 2.3 times higher than $E_{1}$ consumed by the pumps. The ratio between the gross income and the cost of pumping energy is:

$$
\frac{E_{2} P_{2}}{E_{1} P_{1}}=2.3 \frac{P_{2}}{P_{1}}=2.3 \times 4=9.2
$$

What ensures the recovery of investment in the primary (the one in the secondary being amortized) in a time $\mathrm{T}_{\mathrm{r}}<8$ years (secondary investment does not enter into consideration, because the investments were amortized hydroelectric power stations) [10]. Considering that the energy needed for pumping high expense represents (considering a function period $\left(\mathrm{T}_{\mathrm{u}}\right)$ of 1,500 hours for AHP) [7] taking into consideration is the preferable option of unparalleled energy. For taking into account wind energy, it is important and unparalleled cost of this energy $\left(\mathrm{p}_{1 \mathrm{e}}\right)$. An evaluation of this cost results from:

$$
\frac{P_{1 e}}{P_{1}}=1.5 \Rightarrow \frac{p_{2}}{p_{1 e}}=2.66
$$

Having regard to this and applying for AHP for the river Barzava will result:

$$
\frac{E_{2} P_{1 e}}{E_{1} p_{1}}=2.3 \frac{p_{2}}{p_{1 e}}=2.3 \times 2.66=6.1
$$

By comparing the ratios of gross revenues and expenditures with the energy needed for pumping data relationships [11] and [12] shall establish a decrease of their value because it replaces a primary energy cheap one with me about $50 \%$ more expensive at pumping water. Analysing the terms of relationship recovery time of the investment, in this case we have:

AHP:

$T_{r}=\frac{1}{V_{b r}-C}$

Where:

$\mathrm{T}_{\mathrm{r}}=$ investment recovery time and must fulfill the condition: $\mathrm{T}_{\mathrm{r}}<\mathrm{T}_{\mathrm{N}}$

$\mathrm{T}_{\mathrm{N}}=$ recovery time of the normed

I=Investments made for the realization of the AHP in the utilization assumption primary

power base of the national energy

$\mathrm{V}_{\mathrm{br}}=$ gross income realized by AHP in the same hypothesis

$\mathrm{C}=$ the annual costs of production in the same hypothesis

Replacing the primary power source to wind power pumping result:
$T_{r e}=\frac{I+\Delta I}{\left(V_{b r}+\Delta V_{b r}\right)-(C+\Delta C)}$

Where:

$\Delta \mathrm{I}$ - the investment that is needed to supplement the replacement power supply

$\Delta V_{b r}=E_{1} p_{1}$ - Additional gross income achieved through the use for other purposes the primary energy taken for pumping from national energy network $\Delta C=E_{1} \cdot \alpha p_{1}$-additional production costs, using wind energy for pumping $\alpha p_{1}=p_{1 e}-p_{1}$-represents the cost of pumping increase energy using wind energy more expensive

In order to achieve the same as AHPE (economic efficiency as well as AHP must: $\mathrm{T}_{\mathrm{r}}=\mathrm{T}_{\mathrm{re}}$,

$$
\frac{1}{V_{b r}-C}=\frac{I+\Delta I}{\left(V_{b r}+\Delta V_{b r}\right)-(C+\Delta C)} \rightarrow \frac{1}{V_{b r}-C}=\frac{\Delta I}{\Delta V_{b r}-\Delta C}=T_{r}
$$

results so that investment should be recovered while at the same time with the investment of additional income realized through use in other purposes of pumping energy, taking into account the increase in the cost of energy from the unparalleled [13].

Taking into account the fact that $\Delta \mathrm{V}_{\mathrm{br}}=\mathrm{E}_{1} \mathrm{p}_{1}$ and $\Delta \mathrm{C}=\alpha \mathrm{E}_{1} \mathrm{p}_{1}$ results:

$$
T_{r}=\frac{\Delta I}{E_{1} p-\alpha E_{1} p_{1}} \text { or } T_{r}=\frac{1}{1-\alpha} \cdot \frac{\Delta I}{E_{1} p_{1}} \mathrm{a} \text { criterion that allows }
$$
setting the degree of increase ( $\alpha$ ) you incur the cost of wind power energy to basic energy, if you know the expenses necessary for the AHP version pump (using energy), additional investment for achieving AHPE and Tr recovery time of AHP.

\section{References}

1. http://stirileprotv.ro/stiri/social/record-eolian-energia-produsa-intimpul-furtunii-desambata-suficienta-pentru-un-oras-mare.html

2. http://www.antena3.ro/romania/centralele-eoliene-produc-energie-incantitati-record-dar-seceta-ar-putea-duce-la-scumpiri-150790.html

3. http://www.adevarul.ro/financiar/ Ce_au_adus_romanilor_baietii_verzi_din_energie_0_621538351.html

4. Toma L (2007) Wind power is gaining renewable energy market, Truth Magazine.

5. Bălăceanu $F$ (2011) Wind farms will increase current $4 \%$ this year, financial truth.

6. Pavel D (1973) Prospects for hydro transformers and complex Hydro Review No. 6.

7. Pavel D (1972) Transformers hydropower in mining and construction in Romania Magazine Hidrotehnica.

8. Kaltschmitt M, Streicher W, Wiese A (2007) Renewable energy. Technology, economics and environment, Springer, Berlin/Heidelberg.

9. Mueller, Michael, De Cesare, Giovanni (2009) Pump storage Hydro power plant Limmern Hydraulic model tests of the intake structures, upper basin Muttsee.

10. Peng W, Chen D (2010) Some considerations on the development of pumped hydroelectric storage power station, State Electricity Regulatory Commission, People's Republic of China.

11. Yang CJ, Jackson R (2011) Opportunities and barriers to pumped-hydro energy storage in the United States. Renewable and Sustainable Energy Reviews 15: 839-844.

12. Zuber M (2011) Renaissance for Pumped Storage in Europe, Hydro Review Worldwide 19, Guided Tour on Wind Energy, Danish Wind Industry Association. 
Citation: Minda CB (2016) The Study of using Wind Energy to Hydropower Designs with Pump. Hydrol Current Res 7: 224. doi: 10.4172/2157-7587.1000224

Page 5 of 5

13. The European Wind Energy Association. 